\title{
Four-Terminal Tandem Solar Cell with Dye-Sensitized and PbS Colloidal Quantum-Dot-Based Subcells
}

\author{
Lin Yuan, Hannes Michaels, Rajarshi Roy, Malin Johansson, Viktor Öberg, Aneta Andruszkiewicz, \\ Xiaoliang Zhang, Marina Freitag,* and Erik M. J. Johansson*
}

Cite This: ACS Appl. Energy Mater. 2020, 3, 3157-3161

Read Online

\section{ACCESS \\ Wl Metrics \& More \\ Article Recommendations \\ Supporting Information}
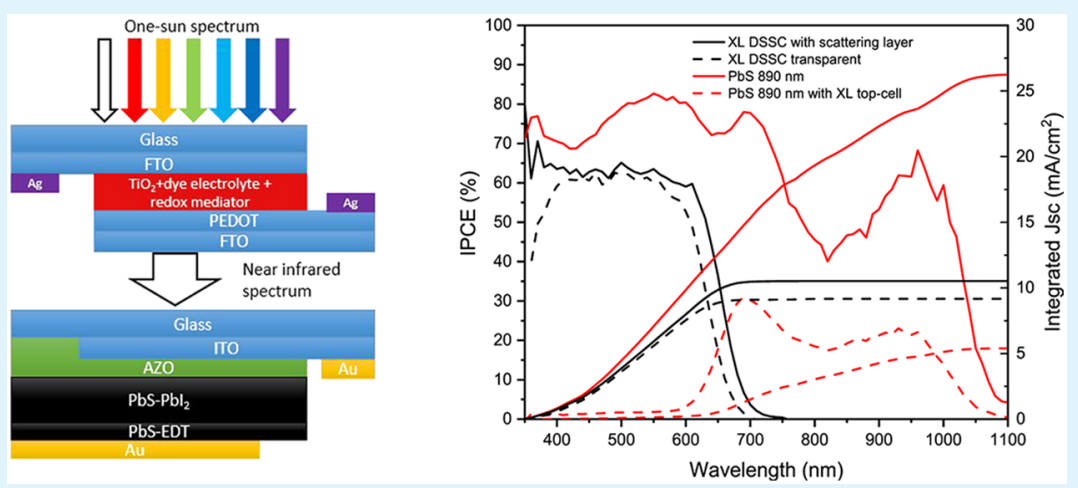

ABSTRACT: In this work, high-performance four-terminal solution-processed tandem solar cells were fabricated by using dyesensitized solar cells (DSSCs) as top-cells and lead sulfide ( $\mathrm{PbS}$ ) colloidal quantum dot solar cells (CQDSCs) as bottom-cells. For dye-sensitized top-cells, three different dye combinations were used while the titanium dioxide $\left(\mathrm{TiO}_{2}\right)$ scattering layer was removed to maximize the transmission. For the $\mathrm{PbS}$ bottom-cells, quantum dots with different sizes were compared. Over $12 \%$ power conversion efficiency has been achieved by using the XL dye mixture and $890 \mathrm{~nm} \mathrm{PbS}$ QDs, which shows a significant efficiency enhancement when compared to single DSSC or CQDSC subcells.

KEYWORDS: PbS, quantum dot solar cell, dye-sensitized solar cell, solution-processed, four-terminal tandem

Olloidal quantum dot (CQD)-based materials have an excellent potential for many different optoelectronic applications, ${ }^{1}$ such as solar cells, ${ }^{2-5}$ light-emitting diodes, ${ }^{6,7}$ gas sensors, ${ }^{8,9}$ and photodetectors. ${ }^{10,11}$ CQDs have attracted a lot of attention because of the tunable band gap, low-cost earthabundant materials, and possibility for solution-based preparation processes. A PbS colloidal quantum dot solar cell (CQDSC) was first reported in 2005, ${ }^{12}$ and it achieved over $1 \%$ power conversion efficiency (PCE) in 2008 by K. W. Johnston. ${ }^{13}$ After a decade, the efficiency of the PbS CQDSC is beyond $12 \%$ by using a solution-phase ligand exchange method, and the efficiency was stable for over several weeks under ambient conditions without encapsulation. ${ }^{14}$ Moreover, the $\mathrm{PbS} \mathrm{CQD}$ also offers a possibility to fabricate other advanced photovoltaic devices, such as flexible solar cells, ${ }^{15}$ semitransparent devices, ${ }^{5}$ as well as hot-carrier or multiple exciton generation devices. ${ }^{16}$

The dye-sensitized solar cell, DSSC, has attracted researchers' attention since the early 1990s due to low-cost materials, a simple fabrication process, low toxicity, and excellent ambient light harvesting ability. ${ }^{17}$ Around 12\% PCE under AM 1.5 condition has been achieved for DSSCs, and over $28 \%$ under ambient light condition, ${ }^{18}$ but the large band gap of the most efficient DSSCs may be a drawback to achieve a higher performance because the photons with energy lower than the band gap are wasted. Therefore, it is important to find a way to take advantage of those photons with lower energy to generate more power.

Multijunction solar cells, or tandem solar cells, have been shown to be an effective way to harvest light from a large part of the solar spectrum. It has been proven that increasing the number of junctions in a multijunction device is an efficient way to overcome the Shockley-Queisser limit, which is 33\% PCE for a single junction device. ${ }^{19}$ The PbS CQD has shown an excellent ability of harvesting the near-infrared spectrum, which allows researchers to use this material to fabricate bottom-cells for tandem structure devices. Within the

Received: January 7, 2020

Accepted: March 25, 2020

Published: March 25, 2020 

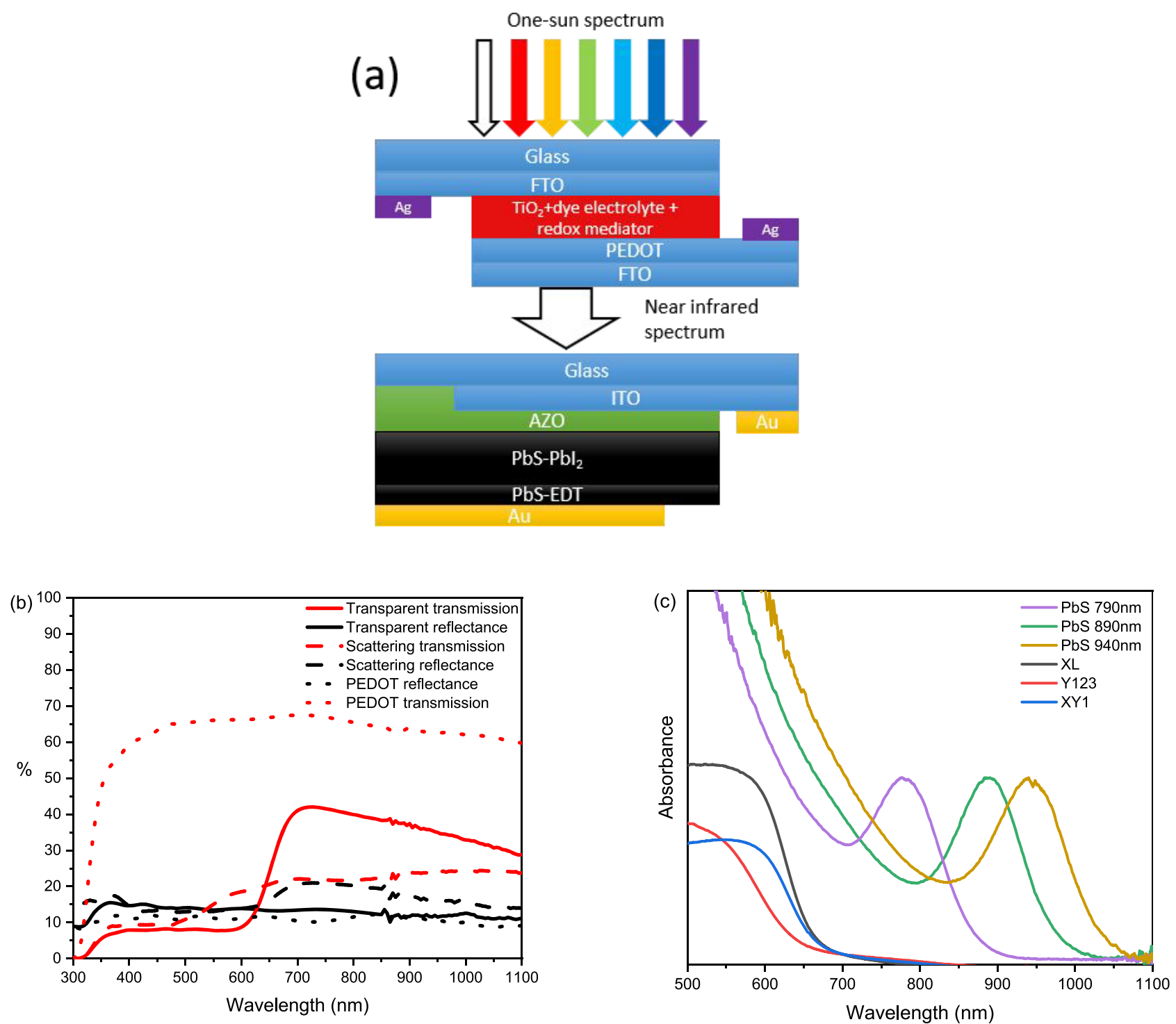

Figure 1. (a) Schematic of the four-terminal tandem structure based on the DSSC and CQDSC. (b) Transmission, reflectance, and absorption spectra for XL DSSCs with and without the scattering layer. (c) UV-vis-NIR absorbance for different dye mixtures and quantum dots with different sizes.

literature, researchers have combined different top-cell materials with $\mathrm{PbS}$ subcells. For example, the $\mathrm{CdTe} / \mathrm{PbS}$ tandem solar cell has achieved over $9 \% \mathrm{PCE}^{20}$ the $\mathrm{PbS} / \mathrm{PbS}$ tandem structure approaches $9 \%$ by using the PbS CQD with a different band gap as subcells, ${ }^{21,22}$ while a theoretical simulation has shown that a perovskite/ $\mathrm{PbS}$ tandem structure can achieve $43 \%$ PCE. $^{19,23}$ Also, a tandem structure DSSC has been proven as a reliable tandem structure photovoltaic device in recent years. ${ }^{24-27}$ However, to the best of our knowledge, the $\mathrm{DSSC} / \mathrm{PbS}$ tandem structure has not previously been investigated.

This work investigates the possibility of making a fourterminal tandem solar cell by using a DSSC and PbS CQDSC as the top-cell and bottom-cell, respectively. We comprehensively test and analyze the combination of three different dye mixtures (Y123, XY1, and XL) and three different sizes of PbS CQD (absorbance peak 790, 890, and $940 \mathrm{~nm}$ ) in tandem solar cells under one-sun conditions.

The four-terminal tandem system contains a DSSC as the top-cell and a PbS CQDSC as the bottom-cell. For the DSSC, we fabricated the cell with a structure of $\mathrm{FTO} / \mathrm{c}-\mathrm{TiO}_{2} / \mathrm{mp}$ $\mathrm{TiO}_{2} /$ dye with a redox electrolyte and PEDOT/FTO backcontact. The PbS CQDSC was fabricated with the ITO/AZO/ $\mathrm{PbS}-\mathrm{PbI}_{2} / \mathrm{PbS}$-EDT/Au structure. The $\mathrm{PbS}-\mathrm{PbI}_{2}$ layer was deposited by a one-step method after solution ligand exchange.

The schematic of the four-terminal tandem solar cell is shown in Figure 1a. Usually DSSCs are fabricated with a $\mathrm{TiO}_{2}$ light scattering layer to improve the absorption of light in the devices. However, the scattering layer reduces the light transmission because it is not transparent. To improve the transmission of light to the PbS-based bottom-cell, we removed the $\mathrm{TiO}_{2}$ scattering layer, and the transmission was increased from less than $30 \%$ to over $40 \%$, which was mainly due to the reduction of reflectance (see Figure $1 \mathrm{~b}$ ). However, the overall transmission was still low when compared with topcells with other materials, e.g., perovskite. ${ }^{28,29}$ The main transmission loss was due to poor transmission of the PEDOT back-contact, which caused over $30 \%$ optical losses. It should also be noticed that the reduction of transmission of light through the DSSC without a scattering layer after $700 \mathrm{~nm}$ was 
due to the light absorption and reflection from the FTO front contact.

We first compared the performance of the DSSCs with different dye combinations and the effect of the removal of the scattering layer for the DSSCs. As shown in Figure 2, after the

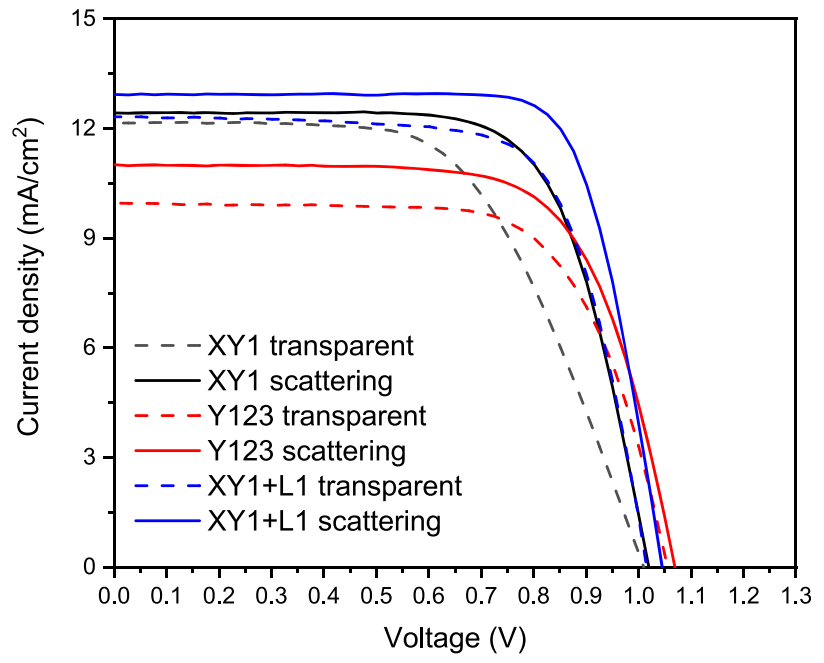

Figure 2. Current-voltage $(J-V)$ measurements under illumination $\left(1000 \mathrm{~W} / \mathrm{m}^{2}, \mathrm{AM} 1.5 \mathrm{G}\right)$ for DSSCs with different dye combinations both for devices with a scattering layer ("scattering") and for devices without the scattering layer ("transparent").

scattering layer was removed, the PCE of XL, XY1, and Y123 dye decreased from $10.20 \%, 9.0 \%$, and $8.11 \%$ to $8.85 \%, 7.17 \%$, and $7.19 \%$, respectively. For the DSSC with Y123 dye, the main reason for the efficiency reduction is that the Y123 dye has a poor light absorption, and removing the scattering layer will therefore reduce the $J_{s c}$ dramatically. On the other hand, though XY1 dye has a better light absorption, the removal of the scattering layer reduces the fill factor (FF) significantly which causes a lower efficiency. By using the XY1 and L1 dye cocktail, the light absorption is enhanced dramatically, so removing the scattering layer will not cause a significant impact on $J_{\text {sc }}$

We then measured the performance of differently sized $\mathrm{PbS}$ CQDSCs and also measured the performance for the CQDSCs as bottom-cells with an XL DSSC top-cell. As shown in Figure $3 \mathrm{a}$, without the top-cell, the PCE of PbS CQDSC was $8.53 \%$, $10.85 \%$, and $5.23 \%$ for devices based on CQDs with peak light absorption at 940,890 , and $790 \mathrm{~nm}$, respectively. Previous reports have shown that $\mathrm{PbS} \mathrm{CQDs}$ with peak absorption around $900 \mathrm{~nm}$ result in the highest efficiency for the PbS CQD solar cells. ${ }^{3,30,31}$ When the DSSC top-cell was applied on top of the CQDSCs, the PCE of these PbS CQDSCs decreased to $3.64 \%, 1.82 \%$, and $1.78 \%$, for devices based on CQDs with peak light absorption at 890, 940, and $790 \mathrm{~nm}$, respectively. The main loss of the performance was due to the significant reduction of $J_{s c}$ which is expected, since the incident-power-to-current-efficiency (IPCE) shows that the visible light blocked by the DSSC top-cell contributes to over $60 \%$ of $J_{\mathrm{sc}}$ in the CQDSC (Figure $3 \mathrm{~b}$ ). By combining the XL DSSC top-cell and the CQDSC bottom-cell based on CQDs with peak light absorption at $890 \mathrm{~nm}$, the best overall efficiency for the 4-terminal system is $11.7 \%$, which is about a $7.4 \%$ and $41 \%$ relative enhancement when compared to the single junction PbS CQDSC and DSSC, respectively (Table 1). We

Table 1. Performance of Single Cells and of Subcells in the Four-Terminal Tandem Solar Cell, and the Total Efficiency of the Four-Terminal Tandem Solar Cell

\begin{tabular}{lcccc} 
& $\begin{array}{c}V_{\mathrm{oc}} \\
(\mathrm{mV})\end{array}$ & $\begin{array}{c}J_{\mathrm{sc}} \\
\left(\mathrm{mA} / \mathrm{cm}^{2}\right)\end{array}$ & $\begin{array}{c}\mathrm{FF} \\
(\%)\end{array}$ & $\begin{array}{c}\text { PCE } \\
(\%)\end{array}$ \\
$\begin{array}{l}\text { single XL DSSC with scattering } \\
\text { layer }\end{array}$ & 1050 & 12.90 & 75.0 & 10.20 \\
$\begin{array}{l}\text { single PbS CQDSC (based on } \\
\text { CQDs with 890 nm abs. peak) }\end{array}$ & 592 & 28.33 & 64.7 & 10.85 \\
$\begin{array}{l}\text { single XL DSSC without scattering } \\
\text { layer }\end{array}$ & 1018 & 12.30 & 71.0 & 8.85 \\
$\begin{array}{l}\text { PbS CQDSC as bottom-cell (with } \\
\text { XL DSSC as top-cell) }\end{array}$ & 534 & 9.88 & 66.7 & 3.52 \\
$\begin{array}{l}\text { 4-terminal tandem solar cell based } \\
\text { on the XL DSSC (without } \\
\text { scattering layer) and PbS CQDSC } \\
\text { (based on CQDs with 890 nm }\end{array}$ & & & & 12.37 \\
abs. peak) & & & & \\
\hline
\end{tabular}

can therefore observe a clear enhancement of the performance due to the better utilization of the infrared light by combining the DSSC with a CQDSC, and this first demonstration paves the way for future DSSC/CQDSC tandem cells with further
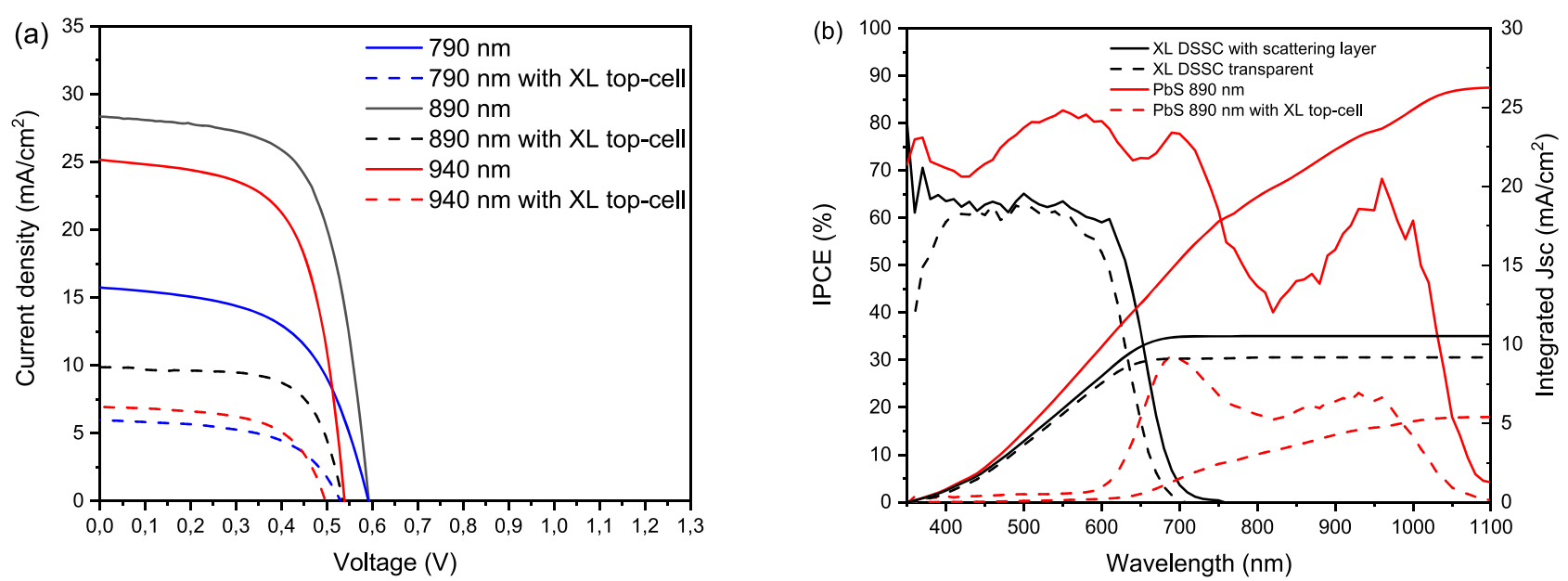

Figure 3. (a) Current density-voltage $(J-V)$ measurements under illumination $\left(1000 \mathrm{~W} / \mathrm{m}^{2}, \mathrm{AM} 1.5 \mathrm{G}\right)$ for different size PbS CQDSCs with and without the XL DSSC top-cell. (b) IPCE and calculated $J_{\mathrm{sc}}$ of XL DSSC and $890 \mathrm{~nm}$ PbS CQDSC under different conditions. 
improved performance. Furthermore, the rather similar currents from the DSSC top-cell and PbS bottom-cell is interesting, and gives a possibility to fabricate a two-terminal tandem structure in the future. However, to achieve very highly performing tandem cells, further work is needed on the light management to reduce the infrared light reflection and absorption within the DSSC device.

In conclusion, we have demonstrated a high-performance four-terminal tandem solar cell by applying a dye-sensitized solar cell as the top-cell and a PbS colloidal quantum dot solar cell as the bottom-cell. Three different types of dyes (XL, XY1, and Y123) and three different PbS CQDs (with absorbance peak at 790, 890, and $940 \mathrm{~nm}$ ) have been examined. The PbS CQDSC with CQDS absorption peak at $890 \mathrm{~nm}$ shows the best performance, which boosts the performance of the DSSC by $\sim 41 \%$ relative for the $\mathrm{XL}$ mixed dye, $\sim 21 \%$ for $\mathrm{XY} 1$, and $\sim 31 \%$ for Y123. We therefore observe a clear enhancement of the performance due to the better utilization of the infrared light by combining the DSSC with a CQDSC, which shows that DSSC/CQDSC tandem cells may be a very interesting alternative for future high-efficiency devices.

\section{ASSOCIATED CONTENT}

\section{SI Supporting Information}

The Supporting Information is available free of charge at https://pubs.acs.org/doi/10.1021/acsaem.0c00030.

Experimental details, $J-V$ plot, and a summary of solar cell performance (PDF)

\section{AUTHOR INFORMATION}

\section{Corresponding Authors}

Marina Freitag - Department of Chemistry-Ångström, Physical Chemistry, Uppsala University, 75120 Uppsala, Sweden; (1) orcid.org/0000-0002-4954-6851;

Email: marina.freitag@kemi.uu.se

Erik M. J. Johansson - Department of Chemistry-Ångström, Physical Chemistry, Uppsala University, 75120 Uppsala, Sweden; Orcid.org/0000-0001-9358-8277;

Email: erik.johansson@kemi.uu.se

\section{Authors}

Lin Yuan - Department of Chemistry-Ångström, Physical Chemistry, Uppsala University, 75120 Uppsala, Sweden; (1) orcid.org/0000-0003-1038-9980

Hannes Michaels - Department of Chemistry-Ångström, Physical Chemistry, Uppsala University, 75120 Uppsala, Sweden

Rajarshi Roy - Department of Chemistry-Ångstrom, Physical Chemistry, Uppsala University, 75120 Uppsala, Sweden

Malin Johansson - Department of Chemistry-Ångström, Physical Chemistry, Uppsala University, 75120 Uppsala, Sweden; $\odot$ orcid.org/0000-0003-2046-1229

Viktor Öberg - Department of Chemistry-Ångström, Physical Chemistry, Uppsala University, 75120 Uppsala, Sweden

Aneta Andruszkiewicz - Department of Chemistry-Ångström, Physical Chemistry, Uppsala University, 75120 Uppsala, Sweden

Xiaoliang Zhang - Department of Chemistry-Ångström, Physical Chemistry, Uppsala University, 75120 Uppsala, Sweden; School of Materials Science and Engineering, Beihang University, Beijing 100191, China; 이이.org/0000-00022847-7359
Complete contact information is available at:

https://pubs.acs.org/10.1021/acsaem.0c00030

\section{Notes}

The authors declare no competing financial interest.

\section{ACKNOWLEDGMENTS}

The authors acknowledge the financial support obtained from the Swedish Energy Agency, Olle Engkvist Foundation, and ÅForsk. This work was also supported by the National Natural Science Foundation of China (51872014), Recruitment Program of Global Experts, and the 111 Project (B17002). We acknowledge experimental assistance from Leif Häggman (Physical Chemistry, Uppsala).

\section{REFERENCES}

(1) Kagan, C. R.; Lifshitz, E.; Sargent, E. H.; Talapin, D. V. Building devices from colloidal quantum dots. Science (Washington, DC, U. S.) 2016, 353 (6302), aac5523.

(2) Zhang, Z.; Chen, Z.; Zhang, J.; Chen, W.; Yang, J.; Wen, X.; Wang, B.; Kobamoto, N.; Yuan, L.; Stride, J. A.; Conibeer, G. J.; Patterson, R. J.; Huang, S. Significant Improvement in the Performance of PbSe Quantum Dot Solar Cell by Introducing a CsPbBr3Perovskite Colloidal Nanocrystal Back Layer. Adv. Energy Mater. 2017, 7 (5), 1601773.

(3) Hu, L.; Huang, S.; Patterson, R.; Halpert, J. E. Enhanced mobility in $\mathrm{PbS}$ quantum dot films: Via $\mathrm{PbSe}$ quantum dot mixing for optoelectronic applications. J. Mater. Chem. C 2019, 7 (15), 4497502.

(4) Chen, Z.; Zhang, Z.; Yang, J.; Chen, W.; Teh, Z. L.; Wang, D.; Yuan, L.; Zhang, J.; Stride, J. A.; Conibeer, G. J.; Patterson, R. J.; Huang, S. Improving carrier extraction in a PbSe quantum dot solar cell by introducing a solution-processed antimony-doped SnO2buffer layer. J. Mater. Chem. C 2018, 6 (37), 9861-6.

(5) Zhang, X.; Öberg, V. A.; Du, J.; Liu, J.; Johansson, E. M. J. Extremely lightweight and ultra-flexible infrared light-converting quantum dot solar cells with high power-per-weight output using a solution-processed bending durable silver nanowire-based electrode. Energy Environ. Sci. 2018, 11 (2), 354-64.

(6) Pradhan, S.; Di Stasio, F.; Bi, Y.; Gupta, S.; Christodoulou, S.; Stavrinadis, A.; Konstantatos, G. High-efficiency colloidal quantum dot infrared light-emitting diodes via engineering at the suprananocrystalline level. Nat. Nanotechnol. 2019, 14, 72.

(7) Li, G.; Rivarola, F. W. R.; Davis, N.J.L.K.; Bai, S.; Jellicoe, T. C.; De La Peña, F.; Hou, S.; Ducati, C.; Gao, F.; Friend, R. H.; Greenham, N. C.; Tan, Z. K. Highly Efficient Perovskite Nanocrystal Light-Emitting Diodes Enabled by a Universal Crosslinking Method. Adv. Mater. 2016, 28 (18), 3528-34.

(8) Liu, H.; Li, M.; Voznyy, O.; Hu, L.; Fu, Q.; Zhou, D.; Xia, Z.; Sargent, E. H.; Tang, J. Physically flexible, rapid-response gas sensor based on colloidal quantum dot solids. Adv. Mater. 2014, 26 (17), 2718-24.

(9) Song, Z.; Huang, Z.; Liu, J.; Hu, Z.; Zhang, J.; Zhang, G.; Yi, F.; Jiang, S.; Lian, J.; Yan, J.; Zang, J.; Liu, H. Fully Stretchable and Humidity-Resistant Quantum Dot Gas Sensors. ACS Sensors. 2018, 3 (5), 1048-55.

(10) Tang, X.; Ackerman, M. M.; Chen, M.; Guyot-Sionnest, P. Dual-band infrared imaging using stacked colloidal quantum dot photodiodes. Nat. Photonics 2019, 13 (4), 277-82.

(11) Wei, Y.; Ren, Z.; Zhang, A.; Mao, P.; Li, H.; Zhong, X.; Li, W.; Yang, S.; Wang, J. Hybrid Organic/PbS Quantum Dot Bilayer Photodetector with Low Dark Current and High Detectivity. Adv. Funct. Mater. 2018, 28 (11), 1706690.

(12) MCDONALD, S. A.; KONSTANTATOS, G.; ZHANG, S.; CYR, P. W.; KLEM, E. J. D.; LEVINA, L.; SARGENT, A. E. H. Solution-processed $\mathrm{PbS}$ quantum dot infrared photodetectors and photovoltaics. Nat. Mater. 2005, 4 (2), 138. 
(13) Johnston, K. W.; Pattantyus-Abraham, A. G.; Clifford, J. P.; Myrskog, S. H.; MacNeil, D. D.; Levina, L.; Sargent, E. H. Schottkyquantum dot photovoltaics for efficient infrared power conversion. Appl. Phys. Lett. 2008, 92 (15), 151115.

(14) Xu, J.; Voznyy, O.; Liu, M.; Kirmani, A. R.; Walters, G.; Munir, R.; Abdelsamie, M.; Proppe, A. H.; Sarkar, A.; Arquer, F. P. G.; Wei, M.; Sun, B.; Liu, M.; Ouellette, O.; Quintero-bermudez, R.; Li, J.; Fan, J.; Quan, L.; Todorovic, P.; Tan, H.; Hoogland, S.; Kelley, S. O.; Stefik, M.; Amassian, A.; Sargent, E. H. 2D matrix engineering for homogeneous quantum dot coupling in photovoltaic solids. Nat. Nanotechnol. 2018, 13 (6), 456.

(15) Zhang, X.; Jia, D.; Hägglund, C.; Öberg, V. A.; Du, J.; Liu, J.; Johansson, E. M. J. Highly photostable and efficient semitransparent quantum dot solar cells by using solution-phase ligand exchange. Nano Energy 2018, 53, 373-82.

(16) Zhang, Z.; Yang, J.; Wen, X.; Yuan, L.; Shrestha, S.; Stride, J. A.; Conibeer, G. J.; Patterson, R. J.; Huang, S. Effect of Halide Treatments on PbSe Quantum Dot Thin Films: Stability, Hot Carrier Lifetime, and Application to Photovoltaics. J. Phys. Chem. C 2015, 119 (42), 24149-55.

(17) O’Regan, B.; Grätzel, M. A low-cost, high-efficiency solar cell based on dye-sensitized colloidal $\mathrm{TiO} 2$ films. Nature 1991, 353 (6346), 737-40.

(18) Freitag, M.; Teuscher, J.; Saygili, Y.; Zhang, X.; Giordano, F.; Liska, P.; Hua, J.; Zakeeruddin, S. M.; Moser, J. E.; Grätzel, M.; Hagfeldt, A. Dye-sensitized solar cells for efficient power generation under ambient lighting. Nat. Photonics 2017, 11 (6), 372-8.

(19) Karani, A.; Yang, L.; Bai, S.; Futscher, M. H.; Snaith, H. J.; Ehrler, B.; Greenham, N. C.; Di, D. Perovskite/Colloidal Quantum Dot Tandem Solar Cells: Theoretical Modeling and Monolithic Structure. ACS Energy Lett. 2018, 3 (4), 869-74.

(20) Crisp, R. W.; Pach, G. F.; Kurley, J. M.; France, R. M.; Reese, M. O.; Nanayakkara, S. U.; Macleod, B. A.; Talapin, D. V.; Beard, M. C.; Luther, J. M. Tandem Solar Cells from Solution-Processed CdTe and $\mathrm{PbS}$ Quantum Dots Using a $\mathrm{ZnTe}-\mathrm{ZnO}$ Tunnel Junction. Nano Lett. 2017, 17 (2), 1020-7.

(21) Shi, G.; Wang, Y.; Liu, Z.; Han, L.; Liu, J.; Wang, Y.; Lu, K.; Chen, S.; Ling, X.; Li, Y.; Cheng, S.; Ma, W. Stable and Highly Efficient $\mathrm{PbS}$ Quantum Dot Tandem Solar Cells Employing a Rationally Designed Recombination Layer. Adv. Energy Mater. 2017, 7 (15), 1602667.

(22) Gao, Y.; Zheng, J.; Chen, W.; Yuan, L.; Teh, Z. L.; Yang, J.; Cui, X.; Conibeer, G.; Patterson, R.; Huang, S. Enhancing PbS Colloidal Quantum Dot Tandem Solar Cell Performance by Graded Band Alignment. J. Phys. Chem. Lett. 2019, 10 (19), 5729-34.

(23) Zhang, Y.; Gu, M.; Li, N.; Xu, Y.; Ling, X.; Wang, Y.; Zhou, S.; Li, F.; Yang, F.; Ji, K.; Yuan, J.; Ma, W. Realizing solution-processed monolithic $\mathrm{PbS} \mathrm{QDs} /$ perovskite tandem solar cells with high UV stability. J. Mater. Chem. A 2018, 6 (48), 24693-701.

(24) Eom, Y. K.; Kang, S. H.; Choi, I. T.; Yoo, Y.; Kim, J.; Kim, H. K. Significant light absorption enhancement by a single heterocyclic unit change in the $\pi$-bridge moiety from thieno[3,2-b]benzothiophene to thieno[3,2-b]indole for high performance dyesensitized and tandem solar cells. J. Mater. Chem. A 2017, 5 (5), 2297-308.

(25) Kwon, J.; Im, M. J.; Kim, C. U.; Won, S. H.; Kang, S. B.; Kang, S. H.; Choi, I. T.; Kim, H. K.; Kim, I. H.; Park, J. H.; Choi, K. J. Twoterminal DSSC/silicon tandem solar cells exceeding $18 \%$ efficiency. Energy Environ. Sci. 2016, 9 (12), 3657-65.

(26) Baranwal, A. K.; Shiki, T.; Ogomi, Y.; Pandey, S. S.; Ma, T.; Hayase, S. Tandem dye-sensitized solar cells with a back-contact bottom electrode without a transparent conductive oxide layer. RSC Adv. 2014, 4 (88), 47735-42.

(27) Baranwal, A. K.; Fujikawa, N.; Hayat, A.; Ogomi, Y.; Pandey, S. S.; Ma, T.; Hayase, S. Combining novel device architecture and NIR dye towards the fabrication of transparent conductive oxide-less tandem dye sensitized solar cells. Appl. Phys. Express 2015, 8 (10), 102301.
(28) Sheng, R.; Ho-Baillie, A. W. Y.; Huang, S.; Keevers, M.; Hao, X.; Jiang, L.; Cheng, Y. B.; Green, M. A. Four-Terminal Tandem Solar Cells Using $\mathrm{CH} 3 \mathrm{NH} 3 \mathrm{PbBr} 3$ by Spectrum Splitting. J. Phys. Chem. Lett. 2015, 6 (19), 3931-4.

(29) Zhao, D.; Wang, C.; Song, Z.; Yu, Y.; Chen, C.; Zhao, X.; Zhu, K.; Yan, Y. Four-Terminal All-Perovskite Tandem Solar Cells Achieving Power Conversion Efficiencies Exceeding 23\%. ACS Energy Lett. 2018, 3 (2), 305-6.

(30) Hu, L.; Patterson, R. J.; Hu, Y.; Chen, W.; Zhang, Z.; Yuan, L.; Chen, Z.; Conibeer, G. J.; Wang, G.; Huang, S. High Performance $\mathrm{PbS}$ Colloidal Quantum Dot Solar Cells by Employing SolutionProcessed CdS Thin Films from a Single-Source Precursor as the Electron Transport Layer. Adv. Funct. Mater. 2017, 27, 17036871703687.

(31) Hu, L.; Zhang, Z.; Patterson, R. J.; Hu, Y.; Chen, W.; Chen, C.; Li, D.; Hu, C.; Ge, C.; Chen, Z.; Yuan, L.; Yan, C.; Song, N.; Teh, Z. L.; Conibeer, G. J.; Tang, J.; Huang, S. Achieving high-performance $\mathrm{PbS}$ quantum dot solar cells by improving hole extraction through $\mathrm{Ag}$ doping. Nano Energy 2018, 46 (Nov), 212-219. 